\title{
Pulmonary aspergilloma: analysis of prognosis in relation to haemoptysis and survey of treatment
}

\author{
JONATHAN JEWKES, PHILIP H KAY, MATHIAS PANETH, KENNETH M CITRON
}

From the Brompton Hospital, London

ABSTRACT From 1956 to 198085 patients were admitted to the Brompton Hospital, London, with pulmonary aspergilloma. The mean follow-up period was 8.7 years and $85 \%$ of patients were followed for five years or until death if this was earlier. There were 41 deaths, 27 from respiratory causes: 11 from pneumonia, six from chronic respiratory failure, seven after surgery for aspergilloma, and three from haemoptysis. Medical treatment alone was given to 36 patients, of whom three died of haemoptysis. Systemic antifungal treatment was given to 18 patients without benefit. Intracavitary antifungals were helpful in three out of 10 patients. Surgical resection was performed in 41 patients, of whom three $(7 \%)$ died after operation and a further six $(15 \%)$ developed major complications. Cavernostomy was performed in nine patients considered unfit for resection; four died after operation. Haemoptysis was absent or minor in $\mathbf{4 0}$ patients, of whom 19 were treated medically and 18 by resection, with similar five-year survival rates of $65 \%$ and $75 \%$. Frank or major haemoptysis occurred in 45 patients, of whom 17 were treated medically and 23 by resection, with five-year survivals of $41 \%$ and $84 \%(p<0.02)$. The better survival of the surgical group in this retrospective survey may have been due to the selection of patients with better lung function and more localised pulmonary disease. Our observations suggest that surgical resection for aspergilloma should be restricted to patients with severe haemoptysis and adequate pulmonary function. In patients unfit for resection cavernostomy is hazardous.

Many patients with pulmonary aspergillomas suffer from haemoptysis. ${ }^{1-7}$ Episodes of haemoptysis may be treated medically or prevented by surgical resection but the choice of method is contentious. ${ }^{1-5} 8-12$ We undertook a retrospective survey of 85 patients with pulmonary aspergilloma and analysed the results of medical and surgical treatment with special reference to the severity of haemoptysis. This is the largest published series of which we are aware.

\section{Methods}

We obtained case records of 85 patients admitted to the Brompton Hospital, London, with pulmonary aspergilloma from 1956 to 1980 by referring to the hospital's diagnostic index. The criteria for inclusion in the study were the presence of a rounded opacity in a pulmonary cavity on a plain chest radiograph or tomogram ${ }^{13}$ and of serum precipitins to aspergillus

Address for reprint requests: Dr KM Citron, Brompton Hospital, London SW3 6HP.

Accepted 22 March 1983 extracts. ${ }^{14}$ The maximum diameter of the aspergilloma was measured from standard posteroanterior chest radiographs, without correction for magnification effects.

Only patients admitted to hospital were included. During the 25 years management varied between individual physicians and surgeons. Follow-up information was obtained from hospital case records or from a postal questionnaire completed by the patient's local chest physician or general practitioner.

\section{Results}

\section{THE PATIENTS}

There were 53 men and 32 women $(p<0.03$, binomial test). Age at diagnosis ranged from 16 to 73 years (mean 45 years).

The commonest preceding lung lesion was an open healed tuberculous cavity, present in 24 patients $(28 \%)$. Other common lesions were other forms of upper-lobe fibrosis, sarcoidosis, and allergic bronchopulmonary aspergillosis (table 1). Seven patients had fibrotic or cavitatary disease for which no cause was found, and five patients had no known previous 
Table 1 Pre-existing pulmonary disease in 85 patients with aspergilloma

\begin{tabular}{|c|c|c|}
\hline Disease & & $\begin{array}{l}\text { No of } \\
\text { patients }\end{array}$ \\
\hline $\begin{array}{l}\text { Healed pulmonary tuberculosis } \\
\text { Mycobacterium kansasii infection } \\
\text { Sarcoidosis } \\
\text { Allergic bronchopulmonary aspergillosis } \\
\text { Bronchiectasis } \\
\text { Pneumonia and lung abscess } \\
\text { Idiopathic upper lobe fibrosis and/or cavitation } \\
\text { Associated with rheumatoid arthritis } \\
\text { ankylosing spondylitis } \\
\text { Marfan's syndrome } \\
\text { No other disease present }\end{array}$ & $\begin{array}{l}2 \\
2^{*} \\
2 \dagger \\
7\end{array}$ & $\begin{array}{r}24 \\
3 \\
10 \\
10 \\
6 \\
8 \\
13\end{array}$ \\
\hline $\begin{array}{l}\text { Miscellaneous } \\
\text { Pulmonary infarction } \\
\text { Polyarteritis } \\
\text { Fibrosing mediastinitis } \\
\text { Eosinophilic granuloma } \\
\text { Bullous emphysema }\end{array}$ & $\begin{array}{l}2 \\
1 \\
1 \\
1 \\
1\end{array}$ & 6 \\
\hline No known pre-existing pulmonary disease & & 5 \\
\hline Total & & 85 \\
\hline
\end{tabular}

*One further patient, with a lung abscess, also had ankylosing spondylitis.

†Two further patients, with tuberculosis, also had Marfan's syndrome.

lung disease. The primary lesion affected both lungs in 54 patients $(63 \%)$.

Skinprick testing with Aspergillus fumigatus extract gave an immediate positive response in 39 of the 56 patients tested $(70 \%)$. Asthma occurred in 22 patients, of whom 10 had allergic bronchopulmonary aspergillosis. Four patients had Marfan's syndrome and two patients Fallot's tetralogy, one with tuberculosis and one with no previous lung disease. Mycobacterium xenopii infection occurred in two patients, one with polyarteritis and one with allergic aspergillosis. Seven patients had had a partial gastrectomy for peptic ulcer.

Aspergillomas occurred with equal frequency in each lung. All were situated in the upper lobes except for two in the right middle lobe and three in the lower lobes. Three occurred at the apex of the lower lobe after upper lobectomy. The maximum diameter varied from 2 to $10 \mathrm{~cm}$ (mean $4.5 \mathrm{~cm}$ ).

Nineteen patients $(22 \%)$ had more than one aspergilloma; in 12 cases these were bilateral. The interval between the first and second aspergilloma, as judged by review of chest radiographs, was one year or less for 11 patients and two to three years for five patients. In one of these cases and in all three with a longer interval (four to 10 years) the first aspergilloma had been resected before the second appeared.

Spontaneous resolution of the aspergilloma was noted in two patients after five and 17 years respectively. Both developed a second aspergilloma later, one in the same cavity and the other in the contralateral lung.

Seventy-two patients $(85 \%)$ were followed for a minimum of five years unless death supervened, and 25 patients have been followed for 10 years or more. Forty-one patients are known to have died, at a mean of 5.5 years from diagnosis. Thirty-three are known to be alive after a mean period of 9.9 years. Eleven were lost to follow-up, five immediately after discharge and six after a mean period of $8 \cdot 8$ years.

\section{MORT ALITY}

Mortality, calculated by the actuarial survival method, was $31 \%( \pm 5 \% \mathrm{SE})$ at five years, $56 \%$ $( \pm 7 \%)$ at 10 years, and $66 \%( \pm 8 \%)$ at 15 years from diagnosis. The cause of death in 41 patients is shown in table 2 . Of the 36 patients treated medically, three died from haemoptysis. Nine patients died from unrelated diseases; the cause of death could not be discovered in five cases.

Seven patients died after surgery, three after resection and four after cavernostomy. The mortality for pulmonary resection was three out of 41 patients (7\%).

Seventeen patients died of respiratory disease not directly related to the aspergilloma-six from chronic respiratory insufficiency, six (all with compromised pulmonary function) from pneumonia, and five from chronic pulmonary suppuration. Two of the latter group died from cachexia and respiratory failure, two after operations to remove the cavitated lung, and one from massive bleeding.

\section{HAEMOPTYSIS}

Sixty-six patients $(78 \%)$ had haemoptysis at some stage. Patients were grouped according to the worst haemoptysis they had experienced: group 1-no haemoptysis (14 patients); group 2-minor haemoptysis in which the sputum was streaked or stained with blood (26 patients); group 3-frank haemoptysis with expectoration of pure blood (24 patients); group 4 -major haemoptysis exceeding $150 \mathrm{ml}$ in 24 hours $^{1}$ (21 patients).

Table 2 Deaths in 85 patients with aspergilloma

\begin{tabular}{|c|c|}
\hline Cause of death & $\begin{array}{l}\text { No of } \\
\text { patients }\end{array}$ \\
\hline $\begin{array}{l}\text { Respiratory disease other than aspergilloma } \\
\text { Acute pneumonia } \\
\text { Chronic suppurative pneumonia* } \\
\text { Chronic respiratory insufficiency }\end{array}$ & $\begin{array}{l}6 \\
5 \\
6\end{array}$ \\
\hline $\begin{array}{l}\text { After surgery for aspergilloma } \\
\text { Pulmonary resection } \\
\text { Cavernostomy }\end{array}$ & $\begin{array}{l}3 \\
4\end{array}$ \\
\hline $\begin{array}{l}\text { Bleeding from aspergilloma } \\
\text { Non-respiratory causes } \\
\text { Not known }\end{array}$ & $\begin{array}{l}3 \\
9 \\
5\end{array}$ \\
\hline Total deaths & 41 \\
\hline
\end{tabular}

*See text (p 577, last para). 
The severity of haemoptysis was not related to the size or number of aspergillomas or to the nature of the underlying lung diseases, erythrocyte sedimentation rate, blood eosinophil count, or skinprick test results.

Frank haemoptysis preceded major haemoptysis by six months to three years in 12 patients in group 4 . The other nine patients had no haemoptysis before their first major bleed. The first major haemoptysis led to the diagnosis of aspergilloma in eight patients, occurred within a year of diagnosis in four, and a mean of three years from the diagnosis in nine patients.

All 21 patients with major haemoptysis survived their first bleed with conservative treatment. Eight underwent surgery within a few weeks. Recurrent major haemoptysis occurred in eight of the remaining 13 patients after intervals ranging from two weeks to seven years (median six months).

Eight patients in group 4 were never treated surgically. Three died from haemoptysis two weeks, six weeks, and three years after their first major haemoptysis. Three died from unrelated diseases one to six years later and two survived 10 years.

Thirteen patients in group 4 were treated surgically (12 by resection and one by cavernostomy), with three postoperative deaths (including the patient who had a cavernostomy). One patient died six months later from asthma. The remaining nine patients were alive at the time of follow-up.

Thus three patients died directly from haemoptysis and three from surgery to prevent haemoptysis, a total of six patients $-7 \%$ of the whole series.

\section{MEDICAL TREATMENT}

Corticosteroids were given to 10 patients, with improvement in cough, sputum, and general malaise in five. Frank haemoptysis, which had occurred in two patients, continued in one. The aspergilloma enlarged during steroid treatment in two patients.

Specific antifungal agents were given to 33 patients (table 3). Systemic treatment failed to reduce the size of the aspergilloma in any patient, although it was rarely continued for longer than one month. Drug intolerance (nausea or depression or both) occurred in four of 14 patients treated with oral clotrimazole, miconazole, or econazole. Inhaled antifungal agents were also ineffective even after several weeks of use, although no adverse reactions occurred. Improvement in symptoms was unimpressive.

Antifungal drugs were instilled directly into the cavity in 10 patients, either by percutaneous needling or via a bronchoscope positioned at the relevant segmental orifice with the patient in an appropriate posture. Three patients were treated by both methods. In two patients (not included in table 3) a
Table 3 Antifungal treatment (in many cases a combination of treatments) given to 33 patients

\begin{tabular}{|c|c|}
\hline Treatment & $\begin{array}{l}\text { No of patients } \\
\text { (instillations in par- } \\
\text { entheses) }\end{array}$ \\
\hline $\begin{array}{l}\text { Inhaled nebulised antifungals } \\
\text { Natamycin } \\
\text { Brilliant green } \\
\text { Nystatin }\end{array}$ & $\begin{array}{r}14 \\
11 \\
1\end{array}$ \\
\hline $\begin{array}{l}\text { Systemic antifungals } \\
\text { Clotrimazole } \\
\text { Miconazole } \\
\text { Econazole } \\
\text { Amphotericin B } \\
\text { Others }\end{array}$ & $\begin{array}{l}7 \\
5 \\
2 \\
3 \\
3\end{array}$ \\
\hline $\begin{aligned} & \text { Intracavitary instillation } \\
& \text { Route: } \text { Percutaneous } \\
& \text { Bronchoscopic } \\
& \text { Drug: } \\
& \text { Brilliant Green } \\
& \text { Natamycin } \\
& \text { Nystatin } \\
& \text { Others }\end{aligned}$ & $\begin{array}{l}7(38) \\
6(22) \\
8(34) \\
4(7) \\
3(12) \\
2(7)\end{array}$ \\
\hline
\end{tabular}

single attempt at bronchoscopic instillation failed. Three aspergillomas in two patients disappeared over a few months, and one in a third patient shrank considerably, all after treatment with brilliant green. Adverse reactions, often following the earlier instillations, occurred in six patients; they consisted of cough, fever, malaise, chest pain, and clinical or radiological signs of consolidation around the mycetoma. None of these was life threatening. A seventh patient required ventilation for an asthmatic attack after generalised aspiration of brilliant green and radiographic contrast material. Immediate skin reactions to aspergillus extracts were positive in four of these seven patients. Eight of the 10 patients had no haemoptysis after the instillations. Frank haemoptysis occurred some hours after several instillations into each of the bilateral aspergillomas in one patient while another patient, with four previous major haemoptyses, had fatal haemoptysis on the day after her third intracavitary instillation.

\section{SURGERY}

Fifty-three patients were referred for surgery. Two patients, both with ankylosing spondylitis, were considered unsuitable for operation; two patients declined surgery. The operations performed on 49 patients are shown in table 4 . One patient had a cavernostomy for recurrent aspergilloma four years after a lobectomy and died six years later from chronic suppurative pneumonia.

\section{Pulmonary resection}

Forty-one patients underwent pulmonary resection. Their mean FEV, was 1.96 litres and mean FVC 2.911 .

Three patients $(7 \%)$ died within one month of 
Table 4 Operation performed in 49 patients

\begin{tabular}{lrc}
\hline Operation & No of patients \\
\hline Pulmonary resection & 41 \\
Apical segmentectomy & 8 & \\
Lobectomy & 25 & \\
Pleuropneumonectomy & 8 & \multicolumn{2}{c}{$9^{*}$} \\
Cavernostomy & \multicolumn{2}{c}{50} \\
Total & \multicolumn{2}{c}{50}
\end{tabular}

*One patient had a cavernostomy four years after a lobectomy.

surgery. One death was due to sudden, uncontrolled bleeding; a second to bronchopleural fistula and secondary haemorrhage; and the third to respiratory failure after completion of a right pneumonectomy in a patient who had already undergone bilateral lowerlobe lobectomy for bronchiectasis.

Six patients $(15 \%)$ developed major complications. Three required further surgery within 24 hours to control bleeding. Bronchopleural fistula developed in three patients; two of them, after upper-lobe lobectomy in both cases, were successfully treated by intercostal muscle-flap closure of the fistula and a thoracoplasty while the third required long-term tube drainage after a pneumonectomy.

Three patients died within five years of resection. One patient died from asthma six months after pneumonectomy, one from pneumonia two years after lobectomy, and one from massive haemorrhage from a lung abscess. There was no evidence of aspergilloma at necropsy.

Three patients developed radiological evidence of contralateral aspergilloma one to four years after pulmonary resection. Tests for serum aspergillus precipitins gave negative results in one and strongly positive results in two. Eleven patients without evidence of recurrent aspergilloma one to seven years after resection had tests for precipitins, and results were negative in eight, weakly positive in two, and strongly positive in one.

\section{Cavernostomy}

Cavernostomy was performed in nine patients for whom pulmonary resection was considered too hazardous because of their widespread lung disease and poor pulmonary function (mean $\mathrm{FEV}_{1} 1.34 \mathrm{l}$, mean FVC 2.06 l). Two patients came from group 1, two from group 2, four from group 3 and one from group 4. Evacuation of the aspergilloma ${ }^{15}$ was followed by instillation of antifungal agents (brilliant green in one and natamycin in the others) once or twice daily for three to four weeks. ${ }^{16}$

Four patients died after operation (44\%). One died from haemorrhage and one from haemoptysis after developing Serratia marcescens pneumonia. Two other patients died from pneumonia. Both patients became hypotensive and developed pulmonary shadowing on the second postoperative day, shortly after the second natamycin irrigation. The cause of the pneumonia was not apparent at necropsy. Gram-negative septicaemia or an adverse reaction to natamycin are possibilities.

One patient died six years after the cavernostomy during resection of a chronically suppurating lower lobe (with no evidence of aspergilloma). The remaining four patients are alive from three to 17 years after cavernostomy. Two survivors have no radiological evidence of aspergilloma and tests for aspergillus precipitins have given negative results. A third patient, who had bilaterial aspergillomas, has an empty cavernostomy cavity. In the fourth patient the aspergilloma recurred within two months.

\section{Comparison with medical treatment}

Patients treated by pulmonary resection lived longer than patients treated medically. The figure shows the actuarial survival for each form of treatment. The difference in mortality is greater in patients with frank or major haemoptysis (table 5). The figure and

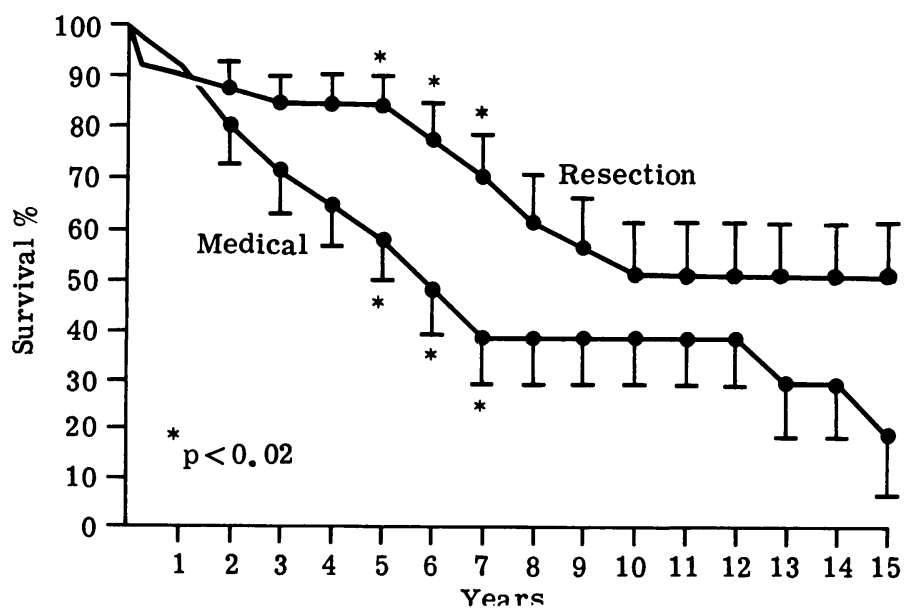

Actuarial survival curves for 40 patients treated by pulmonary resection and 36 patients treated medically. Points show probability of survival and standard error. 
Table 5 Results of treatment according to severity of haemoptysis

\begin{tabular}{|c|c|c|c|c|c|c|c|c|}
\hline & & \multicolumn{3}{|c|}{ Medical treatment $(n=36)$} & \multicolumn{4}{|c|}{ Surgical resection $\left(n=40^{*}\right)$} \\
\hline & & $\begin{array}{l}\text { Died } \\
\text { within } \\
5 y\end{array}$ & $\begin{array}{l}\text { Alive } \\
\text { at } \\
5 y\end{array}$ & $\begin{array}{l}\text { Alive at } \\
\text { follow-up } \\
>5 y\end{array}$ & $\begin{array}{l}\text { Died after } \\
\text { operation }\end{array}$ & $\begin{array}{l}\text { Died } \\
\text { within } \\
5 y\end{array}$ & $\begin{array}{l}\text { Alive } \\
\text { at } \\
5 y\end{array}$ & $\begin{array}{l}\text { Alive at } \\
\text { follow-up } \\
>5 y\end{array}$ \\
\hline $\begin{array}{l}\text { Group } 1 \\
n=12\end{array}$ & No haemoptysis & 3 & 3 & 2 & 0 & 1 & 2 & 1 \\
\hline $\begin{array}{l}\text { Group } 2 \\
n=24\end{array}$ & Blood staining & 3 & 8 & 0 & 1 & 1 & 7 & 4 \\
\hline $\begin{array}{l}\text { Group } \\
n=20\end{array}$ & Frank blood & 5 & 4 & 0 & 0 & 0 & 8 & 3 \\
\hline $\begin{array}{l}\text { Group } 4 \\
n=20\end{array}$ & Major haemoptysis & 5 & 3 & 0 & 2 & 1 & 8 & 1 \\
\hline
\end{tabular}

*Nine patients treated by cavernostomy not included.

table 5 exclude the patient who had a lobectomy followed by a cavernostomy and eight patients treated by cavernostomy alone.) Five-year survivals have been calculated for patients with an adequate follow-up period. In groups 1 and 2,11 of 17 patients treated medically $(65 \%)$ and nine of 12 treated by resection $(75 \%)$ were alive five years later, a non-significant difference. In groups 3 and 4 , seven of 17 patients treated medically $(41 \%)$ survived five years, compared with 16 of $19(84 \%)$ patients treated by pulmonary resection $\left(\chi^{2}=5.45\right.$, $\mathrm{p}<0.02)$. The medically treated patients were of similar age to those treated surgically and had similar-sized aspergillomas. More of the medically treated patients, however, had bilateral lung disease -14 of 17 , compared with nine of 23 treated by resection $(p<0.02)$. Spirometric values were also worse in the medically treated group (mean FEV, $1.36 v 1.911, \mathrm{p}<0.035$; mean FVC $2.38 v 2.831$, $\mathrm{p}=0 \cdot 15$ ). After reviewing the case notes and chest radiographs we consider that resection would have been feasible in 12 of the 17 patients treated medically. Two of these patients had declined an operation, but in the remainder a surgical opinion had not been sought.

\section{Discussion}

The first cases of human aspergillosis were reported by Bennet in $1842 .{ }^{17}$ Fourteen years later Virchow gave the first pathological description of the disease. ${ }^{18}$ It was not until 1947, however, that the first successful resection of an aspergilloma was performed. ${ }^{19}$

The clinical manifestations of aspergillomas vary from an incidental radiological finding to lifethreatening haemoptysis. This survey is confined to patients admitted to hospital and is therefore concerned with more severely affected patients. The survey spans 25 years, during which time different physicians have managed apparently similar cases in different ways. We have made some comparisons of the effects of different treatments, although these were not allocated on a prospective or randomised basis.

We have confirmed that the upper lobes are the predominant site of aspergillomas and that multiple aspergillomas are common, occurring in $22 \%$ of our patients. The size was very variable and bore no relation to the severity of haemoptysis.

The commonest predisposing pulmonary lesions were tuberculosis, other causes of upper-lobe fibrosis, and sarcoidosis. No predisposing cause was found in five patients $(6 \%)$. The association between Marfan's syndrome and aspergilloma has been reported recently. ${ }^{20}$ An unexpectedly large number of patients $(8 \%)$ had previously had a partial gastrectomy.

Spontaneous resolution of the aspergilloma occurred in only two $(5 \%)$ of our medically treated patients. In other, smaller series ${ }^{125}$ the rate of spontaneous resolution varied from zero to $37 \%$. In the larger series reported by the research committee of the British Thoracic and Tuberculosis Association (BTTA) the rate was $5 \%$ over three years. ${ }^{21}{ }^{22}$ Recurrent aspergillomas occurred in three of the 41 (7\%) patients who underwent resection. The BTTA reported that $6 \%$ of their patients with open healed tuberculous cavities developed an aspergilloma during three years of observation. ${ }^{22}$

Patients with aspergilloma have a high mortalitydeath rate $31 \%$ at five years and $56 \%$ at 10 years in our series. The BTTA Research Committee ${ }^{22}$ reported a rate of $6 \%$ per annum, more than three times the expected mortality, but did not specify the causes of death. In our series only 10 of the 27 deaths from respiratory causes were directly attributable to the aspergilloma or its treatment (three were from bleeding and seven followed surgery). The other 17 deaths were from chronic suppurative pneumonia, 
respiratory failure, and acute pneumonia (table 2). The frequency of fatal acute pneumonia reflects the generally poor pulmonary function of these patients. Faulkner $e t a^{1}$ and Varkey and Rose ${ }^{5}$ also found that respiratory insufficiency was the most important cause of death.

Haemoptysis is an important symptom in patients with aspergilloma; it occurred in $83 \%$ of our patients, compared with $64-69 \%$ in other series. ${ }^{12}{ }^{21} 22$ Six (7\%) of our 85 patients died as a direct result of bleeding or after surgery for control of bleeding. Similar deaths occurred in $5 \%$ of 59 patients in the BTTA study, ${ }^{22} 5 \%$ of 42 patients in Faulkner's study, ${ }^{1}$ and $14 \%$ of 36 patients in the study of Karas et al. ${ }^{2}$

We found that major haemoptysis was not related to the size of aspergilloma, the nature of the preexisting lung disease, or markers of hypersensitivity. All three fatal haemoptyses occurred in patients who had already had one major haemoptysis that had settled spontaneously. We found no other factor which could have reliably predicted the minority of patients who suffered severe or fatal haemoptysis.

Specific medical treatment for aspergilloma consists of the administration of antifungal agents. The only successes followed repeated intracavitary instillations of brilliant green. In the 10 patients who were treated aspergillomas resolved in two and shrank in one. Krakowka et al reported 20 patients who had been treated with intracavitary instillations of antifungal agents suspended in a paste ${ }^{23}$; resolution occurred in six and regression in a further six. Ramirez-R used a semi-permanent endobronchial catheter to administer antifungal agents daily and achieved resolution in one of three patients. ${ }^{24}$

Pulmonary resection for aspergilloma is hazardous owing to dense vascular adhesions. Operative mortality in our series was $7 \%$ and similar to that of others. ${ }^{1-5}{ }^{10-12}$ The main postoperative complications were haemorrhage and bronchopleural fistula, each of which occurred in three patients $(7 \%)$. Other authors have reported the development of bronchopleural fistula in 7-25\% of their patients, ${ }^{1-3} 5610$ and this is clearly a problem related to difficult resections in the presence of chronic infection. Nevertheless, these more recent results represent a considerable improvement from the early series reported by Belcher and Plummer in 1960 in which the major complication rate was $38 \%$. $^{9}$

One of the most difficult problems is the management of patients with troublesome symptoms who are unfit for pulmonary resection. After the optimistic report in 1968 by Henderson and Pearson, ${ }^{16}$ evacuation of the aspergilloma via a cavernostomy followed by irrigation with antifungal agents was undertaken in nine patients. Unfortunately the operative mortality was high, four patients dying in the postoperative period. Another approach to the control of haemoptysis is bronchial artery embolisation. Remy et $a l^{25}$ treated 19 patients who had bled from an aspergilloma by this method. Although haemorrhage was readily controlled in the four patients bleeding at the time of the embolisation, three had recurrent haemorrhage within the next few months. There is a single case report of the control of haemoptysis by radiotherapy. ${ }^{26}$

There was a similar mortality rate from haemoptysis in the medically treated group (three out of 36) and after resection (three out of 41). A further four deaths occurred among the nine patients treated by cavernostomy, and clearly this operation should be avoided if possible. If major haemorrhage occurs, lobectomy would appear to be the treatment of choice if pulmonary function is adequate.

Surgery for aspergilloma may also control systemic symptoms. Malaise, fever, and weight loss may be due to secondary infection or to an immunological reaction to the fungus. ${ }^{7}$ These symptoms may not respond to antibiotics and corticosteroids, but patients may benefit from lobectomy.

None of our patients developed invasive aspergillosis. Although this complication of aspergilloma has been reported, ${ }^{27}$ the risk is small, and not sufficient to warrant a general policy of removing all aspergillomas.

In this retrospective study we have attempted to compare the results of medical treatment and resection by comparing survival rates. In patients with minor or no haemoptysis the results of medical treatment in 17 patients and resection in 12 were similar, with five-year survivals of $65 \%$ and $75 \%$. For patients with recurrent frank haemoptysis or a single major bleed the five-year survival was $41 \%$ for 17 patients treated medically and $84 \%$ for 19 patients who had undergone resection. The better survival after resection may have been due to a beneficial effect of surgery or to selection of fitter patients. Pulmonary function was significantly worse in the medically treated group and this would account for the higher mortality rate, since death was usually due to pneumonia or respiratory failure.

We conclude that surgery is not indicated in patients with minor haemoptysis, irrespective of the size of the aspergilloma. In patients with severe haemorrhage pulmonary resection is desirable if pulmonary function is adequate. The management of patients with major haemoptysis who are unfit for resection is difficult. Bronchial artery embolisation may be effective, but if this fails cavernostomy may need to be undertaken despite its high operative risk.

We thank the physicians and surgeons of the Brompton Hospital for permission to report patients 
under their care. We also thank Miss M Rehahn for statistical advice and Miss T Chudleigh for valuable secretarial help.

\section{References}

${ }^{1}$ Faulkner SL, Vernon R, Brown PB, Fisher RD, Bender HW. Haemoptysis and pulmonary aspergilloma: operative versus nonoperative treatment. Ann Thorac Surg 1978;25:389-92.

${ }^{2}$ Karas A, Hankins JR, Attar S, Miller JE, McLaughlin JS. Pulmonary aspergillosis: an analysis of 41 patients. Ann Thorac Surg 1976;22:1-7.

${ }^{3}$ Saab SB, Almond C. Surgical aspects of pulmonary aspergillosis. J Thorac Cardiovasc Surg 1974;68:45560.

${ }^{4}$ Solit RW, McKeowm JJ, Smullens S, Fraimow W. The surgical implications of intracavitary mycetomas (fungus balls). J Thorac Cardiovasc Surg 1971;62:411-20.

${ }^{5}$ Varkey B, Rose HD. Pulmonary aspergilloma. A rational approach to treatment. Am J Med 1976;61:626-31.

${ }^{6}$ Henderson RD, Deslaurier J, Ritcey EL, Delarue NC, Pearson FG. Surgery in pulmonary aspergillosis. $J$ Thorac Cardiovasc Surg 1975;70:1088-92.

${ }^{7}$ McCarthy DS, Pepys J. Pulmonary aspergilloma-clinical immunology. Clin Allergy 1973;3:57-70.

${ }^{8}$ Aslam PA, Eastridge CE, Hughes FA. Aspergillosis of the lung-an eighteen year experience. Chest 1971;59:28-32.

${ }^{9}$ Belcher JR, Plummer NS. Surgery in broncho-pulmonary aspergillosis. Br J Dis Chest 1960;54:335-41.

${ }^{10}$ Garvey J, Crastnopol P, Weisz D, Khan F. The surgical treatment of pulmonary aspergillomas. $J$ Thorac Cardiovasc Surg 1977;74:542-7.

${ }^{11}$ Kilman JW, Ahn C, Andrews NC, Klassen K. Surgery for pulmonary aspergillosis. J Thorac Cardiovasc Surg 1969;57:642-7.

${ }^{12}$ Soltanzadeh H, Wychulis AR, Sadr F, Bolanowski PJ, Nenille WE. Surgical treatment of pulmonary aspergilloma. Ann Surg 1977;186:13-6.

${ }^{13}$ Golberg B. Radiological appearances in pulmonary aspergillosis. Clin Radiol 1962;13:106-14.
${ }^{14}$ Longbottom JL, Pepys J. Pulmonary aspergillosis. Diagnostic and immunological significance of antigens and C-substance in Aspergillus fumigatus.J Pathol Bacteriol 1964;88:141-51.

${ }^{15}$ Loeckell H. Uber die transthorakale Austraumung eines Lungenmycetoma mittels Maurerdrainage. Prax Pneumol 1964;18:757-61.

${ }^{16}$ Henderson AH, Pearson JEG. Treatment of bronchopulmonary aspergillosis with observations on the use of natamycin. Thorax 1968;23:519-23.

${ }^{17}$ Bennet $\mathrm{JH}$. On the parasitic vegetable structures found growing in living animals. Trans $R$ Soc Edinb 1842;15:277-9.

${ }^{18}$ Virchow R. Beitrage zur Lehre von den beim Menschen vorkommenden pflanzlichen Parasiten. Virchow Arch (Pathol Anat) 1856;9:557-61.

${ }^{19}$ Gerstl B, Weidman WH, Newman AV. Pulmonary aspergillosis. Report of two cases. Ann Intern Med 1948;28:662-5.

${ }^{20}$ Bellamy D, Wood JR, Child A, Denison D, Citron KM. Lung disease in Marfan's syndrome. Br J Dis Chest 1980;74:321.

${ }^{21}$ British Tuberculosis Association. Aspergillus in persistent lung cavities after tuberculosis. Tubercle 1968;49:1-11.

${ }^{22}$ British Thoracic and Tuberculosis Association. Aspergilloma and residual tuberculous cavities-the results of a resurvey. Tubercle 1970;51:227-45.

${ }^{23}$ Krakowka P, Traczyk K, Walczak J, Halweg H, Elsner Z, Pawlicka L. Local treatment of aspergilloma of the lung with a paste containing nystatin or amphotericin B. Tubercle 1970;51:184-91.

${ }^{24}$ Ramirez-R J. Pulmonary aspergilloma. Endobronchial treatment. $N$ Engl J Med 1964;271:1281-5.

${ }^{25}$ Remy J, Arnaud A, Fardou H, Giraud R, Voisin C. Treatment of haemoptysis by embolisation of bronchial arteries. Radiology 1977;122:33-7.

${ }^{20}$ Shneerson JM, Emerson PA, Phillips RH. Radiotherapy for massive haemoptysis from an aspergilloma. Thorax 1980;35:953-4.

${ }^{27}$ Anderson CJ, Craig S, Bardana EJ. Allergic bronchopulmonary aspergillosis and bilateral fungus balls terminating in disseminated aspergillosis. Allergy Clin Immunol 1980;65:140-4. 